(2) Open Access Full Text Article

\title{
Expression of Her-2/neu in extrahepatic cholangiocarcinoma
}

\author{
Rania Shamekh ${ }^{1, *}$ \\ Marilin Rosa ${ }^{2, *}$ \\ Zena Sayegh ${ }^{2}$ \\ Masoumeh Ghayouri \\ Richard $\mathrm{Kim}^{3}$ \\ Mokenge P Malafa ${ }^{3}$ \\ Domenico Coppola ${ }^{2}$ \\ 'Department of Pathology, University \\ of South Florida, ${ }^{2}$ Department of \\ Anatomic Pathology, ${ }^{3}$ Department \\ of Gastrointestinal Oncology, H. Lee \\ Moffitt Cancer Center \& Research \\ Institute, Tampa, FL, USA \\ *These authors contributed equally \\ to this work
}

This article was published in the following Dove Press journal:

Pathology and Laboratory Medicine International

15 February 2017

Number of times this article has been viewed

Background: Receptor tyrosine-protein kinase erbB-2, which is also frequently called human epidermal growth factor receptor-2 (Her-2) or Her-2/neu, has been found to be overexpressed in various human cancers.

Hypothesis: The aim of this pilot study was to explore the frequency of Her-2/neu gene amplification and protein expression in extrahepatic cholangiocarcinoma (EHBC). We used the World Health Organization classification criteria for EHBC.

Materials and methods: This was a retrospective study using 88 tissue samples, including 45 samples from non-neoplastic biliary tissue (NNB) and 43 samples of extrahepatic cholangiocarcinoma (EHBC). A tissue microarray including NNB and EHBC was constructed and analyzed by immunohistochemistry (IHC) and dual in situ hybridization for Her-2/neu protein expression and amplification, respectively. The Her-2/neu expression was scored following the guidelines used for the ToGA study.

Results: All NNB samples and all but one EHBC samples showed no expression of Her-2/neu by IHC. The one EHBC case immunohistochemically positive for Her-2/neu had an IHC score of $3+$. Her-2/neu gene amplification was present in two EHBC samples only and included the case found to be positive by IHC.

Conclusion: Our findings are similar to those reported in the literature. Although Her-2/neu overexpression has been documented in many types of cancer, Her-2/neu protein overexpression tends to have no role in the development and/or progression of EHBC.

Keywords: extrahepatic, cholangiocarcinoma, Her-2/neu, ToGA, immunohistochemistry

\section{Introduction}

Extrahepatic cholangiocarcinoma (EHBC) is the second most common biliary tract malignancy ${ }^{1,2}$ with an incidence in the US being 1.2 per 100,000 men and 0.8 per 100,000 women. $^{3}$ EHBC usually affects patients over 65 years of age, with slightly higher rates of whites affected compared to blacks., ${ }^{2,3}$

While most of the EHBCs occur in an otherwise normal liver, $10 \%$ of them are predisposed by chronic inflammatory conditions such as primary sclerosing cholangitis, infestations with liver flukes, choledochal cysts, and hepatic biliary stones., Intraductal papillary neoplasms and biliary intraepithelial neoplasia have been proposed in the latest World Health Organization classification as precursor lesions for the development of EHBC. ${ }^{1}$

Many molecular factors have been related to the pathogenesis of $\mathrm{EHBC}$, such as mutation of the $K$-ras, $p 53$, and $A P C$ genes, as well as the loss of heterozygosity at the $p 53$ and $A P C$ gene loci. ${ }^{5}$ In addition, it has been shown that the methylation profile of 
EHBC often includes the methylation of tumor suppressor genes such as the RASSF1A, p15, p16, APC, E-cad, MGMT, GSTP, RAR- $\beta$, and DAPK. ${ }^{6}$

Human epidermal growth factor receptor-2 (Her-2/neu) is a tyrosine kinase receptor ${ }^{7}$ that stimulates numerous pathways regulating cell proliferation, differentiation, and apoptosis and has been overexpressed and amplified in various cancers. ${ }^{7}$ The amplification and overexpression of the Her-2/neu protooncogene has been described in various malignancies such as breast and ovarian cancer ${ }^{8}$ as well as in gastric cancer. ${ }^{9,10}$

The aim of this study is to investigate the frequency of Her-2/neu overexpression using immunohistochemistry (IHC) and the frequency of Her-2/neu amplification using dual in situ hybridization (DISH) in EHBC.

\section{Materials and methods}

Upon Institutional Review Board approval the histological specimens and reports from 43 patients who underwent resection for EHBC were re-evaluated by two pathologists with interest in gastrointestinal pathology (MG and DC) to confirm the diagnosis for inclusion in the current Her-2/neu study. The patients signed a written informed consent to be part of this study.

\section{Clinicopathologic characteristics}

The patients' ages ranged between 41 and 89 years (mean 66.5 years). Twenty-three of them were female and 20 were male. The tumor ranged in size between 0.5 and $3.7 \mathrm{~cm}$ (mean $1.9 \mathrm{~cm})$. All tumors were extrahepatic adenocarcinomas, intestinal type (World Health Organization classification). Nine tumors were well differentiated, 25 were moderately differentiated, and 9 were poorly differentiated. The clinicopathologic features of the tumors are summarized in Table 1.

\section{Tissue microarrays}

The hematoxylin and eosin stained slides of 43 EHBC patients were selected and the area of tumor was marked. The paraffin block corresponding to the selected slide was used to construct an EHBC tissue microarray (EHBC-TMA). All tissues had been processed for 12 hours in 10\% neutral buffered formalin, a series of graded alcohols, xylene, and paraffin. After processing, each tissue was embedded in histology grade paraffin and then cut on a Leica microtome. A section was picked up on a glass slide and stained with hematoxylin and eosin, and a coverslip was placed on the slide for permanent mounting.

The EHBC-TMA also comprised samples on non-neoplastic biliary tissue (NNB). Three $1 \mathrm{~mm}$ cores from each of the formalin-fixed, paraffin-embedded samples were included in the EHBC-TMA. The NNB samples were collected from the same EHBC patients near the uninvolved surgical margin and away from the tumor. In 2 cases, the NNB samples were taken from specimens resected for non-neoplastic conditions.

\section{Immunohistochemistry}

The usage of EHBC-TMA in our study allowed the entire cohort, NNB and EHBC tissues, to be analyzed on one slide, and the benefits of using TMA are well documented. ${ }^{11} \mathrm{~A}$ known Her-2/neu-positive breast carcinoma was used as a positive control. For negative control, the primary antibody was omitted during the incubation step. The EHBC-TMA was incubated for 16 min with a Her-2/neu rabbit monoclonal antibody (clone 4B5, using the Benchmark XT; Ventana Medical Systems) and detected by ultraview universal DAB detection kit (using the Benchmark XT; Ventana Medical Systems, Inc.). Antigen retrieval was performed using the Ventana Cell Conditioner \#1 for $32 \mathrm{~min}$. The Her-2/neu protein expression was evaluated using the modified ToGA trial scoring criteria established for gastric and gastroesophageal carcinomas ${ }^{12-14}$ as follows: 1) no staining or no membranous staining of tumor cells was scored as " 0 "; 2) tumor cells with faint membrane staining irrespective of the percentage of tumor cells were scored as " $1+$ "; 3 ) tumor cells with weak to moderate membrane staining irrespective of the percentage of tumor cells were scored as " $2+$ "; and 4) tumor cells with strong complete, basolateral, or lateral membrane reactivity irrespective of the percentage of tumor cells were scored as " $3+" .{ }^{14}$ We used the presence of complete, basolateral, or lateral membranous reactivity in $\geq 10 \%$ of cells as the cutoff for positivity, as required by the published guidelines. ${ }^{14}$ The Her-2/neu IHC score was calculated by two independent pathologists (RS and DC) and a consensus score was reached for each specimen.

\section{Dual in situ hybridization}

The Her-2/neu gene amplification by in situ hybridization was performed using the Ventana INFORM HER2 Dual ISH DNA Probe Cocktail assay (Ventana Benchmark Ultra Platform). Analysis of in situ hybridization was performed using a $60 \times$ objective. A manual count of the number of Her-2/neu signals and the number of centromere 17 (CEP17) signals in each individual nucleus was performed using bright field microscopy and a minimum of 20 epithelial cells were evaluated per sample. The ratio of the average number of Her-2/neu gene copies to the average number of $\mathrm{Chr} 17$ copies was calculated manually.

Indeterminate results were obtained due to any of the following: absence of target cells, no tissue present, unable to 
Table I Patients' clinicopathologic characteristics

\begin{tabular}{|c|c|c|c|c|c|}
\hline $\begin{array}{l}\text { Age at diagnosis } \\
\text { (years) }\end{array}$ & Gender & Diagnosis & $\begin{array}{l}\text { Tumor size } \\
(\mathrm{cm})\end{array}$ & Tumor grade & Tumor stage \\
\hline 48 & $\mathrm{~F}$ & Cholangiocarcinoma & 1.5 & Moderately differentiated & PT2NOMX \\
\hline 50 & $\mathrm{~F}$ & Cholangiocarcinoma & 1.7 & Moderately differentiated & PTINOMO \\
\hline 56 & $\mathrm{~F}$ & Cholangiocarcinoma & 3.0 & Moderately differentiated & PTINOMO \\
\hline 57 & $\mathrm{~F}$ & Cholangiocarcinoma & 2.0 & Well differentiated & PTINOMO \\
\hline 57 & $\mathrm{~F}$ & Cholangiocarcinoma & 2.0 & Moderately differentiated & PT3NOMX \\
\hline 58 & $\mathrm{~F}$ & Cholangiocarcinoma & 3.0 & Well differentiated & PT3NOMX \\
\hline 60 & $\mathrm{~F}$ & Cholangiocarcinoma & 1.2 & Moderately differentiated & PT3NIMX \\
\hline 61 & $\mathrm{~F}$ & Cholangiocarcinoma & 1.7 & Moderately differentiated & PTINOMX \\
\hline 61 & $\mathrm{~F}$ & Cholangiocarcinoma & 1.5 & Moderately differentiated & PT2NIMX \\
\hline 62 & $\mathrm{~F}$ & Cholangiocarcinoma & 3.5 & Poorly differentiated & PT3NIMX \\
\hline 62 & $\mathrm{~F}$ & Cholangiocarcinoma & 0.5 & Well differentiated & PT3NOMX \\
\hline 63 & $\mathrm{~F}$ & Cholangiocarcinoma & 3.1 & Moderately differentiated & PT2NOMX \\
\hline 66 & $\mathrm{~F}$ & Cholangiocarcinoma & 1.7 & Well differentiated & PT3NIMX \\
\hline 66 & $\mathrm{~F}$ & Cholangiocarcinoma & 2.0 & Moderately differentiated & PT3NOMX \\
\hline 66 & $\mathrm{~F}$ & Cholangiocarcinoma & 1.7 & Poorly differentiated & PTINIMX \\
\hline 69 & $\mathrm{~F}$ & Cholangiocarcinoma & 1.5 & Poorly differentiated & PTINIMX \\
\hline 75 & $\mathrm{~F}$ & Cholangiocarcinoma & 2.2 & Moderately differentiated & PT3NIMX \\
\hline 77 & $\mathrm{~F}$ & Cholangiocarcinoma & 2.0 & Poorly differentiated & PT3NIMX \\
\hline 78 & $\mathrm{~F}$ & Cholangiocarcinoma & 2.4 & Moderately differentiated & PT3NIMX \\
\hline 82 & $\mathrm{~F}$ & Cholangiocarcinoma & 1.8 & Poorly differentiated & PT3NIMX \\
\hline 89 & $\mathrm{~F}$ & Cholangiocarcinoma & 1.8 & Moderately differentiated & PT3NOMX \\
\hline 67 & $\mathrm{~F}$ & Cholangiocarcinoma & 1.5 & Moderately differentiated & PT3NOMX \\
\hline 41 & M & Cholangiocarcinoma & 1.7 & Poorly differentiated & $\mathrm{PT} \times \mathrm{N} \times \mathrm{MI}$ \\
\hline 58 & M & Cholangiocarcinoma & 1.4 & Poorly differentiated & PT3NOMX \\
\hline 58 & M & Cholangiocarcinoma & 1.3 & Poorly differentiated & PT2NIMX \\
\hline 59 & M & Cholangiocarcinoma & 2.5 & Moderately differentiated & PT2NOMX \\
\hline 61 & M & Cholangiocarcinoma & 1.8 & Well differentiated & PT3NIMX \\
\hline 61 & M & Cholangiocarcinoma & 3.0 & Moderately differentiated & PT3NIMX \\
\hline 64 & M & Cholangiocarcinoma & 2.0 & Poorly differentiated & PT2NIMX \\
\hline 65 & M & Cholangiocarcinoma & 2.2 & Well differentiated & PTINOMX \\
\hline 66 & M & Cholangiocarcinoma & 1.0 & Moderately differentiated & PT2NOMX \\
\hline 68 & M & Cholangiocarcinoma & 2.0 & Well differentiated & $\mathrm{PT} 2 \mathrm{~N} 0 \mathrm{MX}$ \\
\hline 68 & M & Cholangiocarcinoma & 2.5 & Well differentiated & PT3NIMX \\
\hline 70 & M & Cholangiocarcinoma & 1.5 & Moderately differentiated & PTINIMX \\
\hline 70 & M & Cholangiocarcinoma & 1.3 & Moderately differentiated & PT2NOMX \\
\hline 73 & M & Cholangiocarcinoma & 2.5 & Moderately differentiated & PT2NOMX \\
\hline 73 & M & Cholangiocarcinoma & 1.5 & Moderately differentiated & PT3NOMX \\
\hline 76 & M & Cholangiocarcinoma & 1.6 & Moderately differentiated & PT2NOMX \\
\hline 79 & M & Cholangiocarcinoma & 0.5 & Well differentiated & PT4NOMX \\
\hline 80 & M & Cholangiocarcinoma & 1.5 & Moderately differentiated & PT3NIMX \\
\hline 83 & M & Cholangiocarcinoma & 0.7 & Moderately differentiated & PT2NOMX \\
\hline 84 & M & Cholangiocarcinoma & 3.7 & Moderately differentiated & PT3NOMX \\
\hline 74 & $\mathrm{~F}$ & Cholangiocarcinoma & 1.9 & Moderately differentiated & PT3NIMX \\
\hline
\end{tabular}

Abbreviations: $F$, female; $M$, male.

distinguish normal cells from target cells, unacceptable background or weak/absent ISH staining in target cells. A Her-2/ neu:Chr17 ratio of $<2.0$ was considered DISH negative, while a Her-2/neu:Chr17 ratio $\geq 2.0$ was considered DISH positive.

\section{Results}

The characteristics of the 43 subjects, including age, gender, pathological diagnosis, tumor size, tumor grade, and tumor stage, are shown in Table 1.
All NNB samples were negative for Her-2/neu IHC (score 0). We found all but one of the $43 \mathrm{EHBC}$ cases to be negative for Her-2/neu expression. The positive case had an IHC score of 3+(Figure 1A, B). Importantly, the Her-2/neu IHC score was similar for all of the 3 cores taken from this tumor. The scoring was based on the evaluation of the epithelial cells only.

The positive case was a moderately differentiated adenocarcinoma of the bile duct. Neither lymphovascular invasion nor distant metastasis was detected. This tumor had no 
A

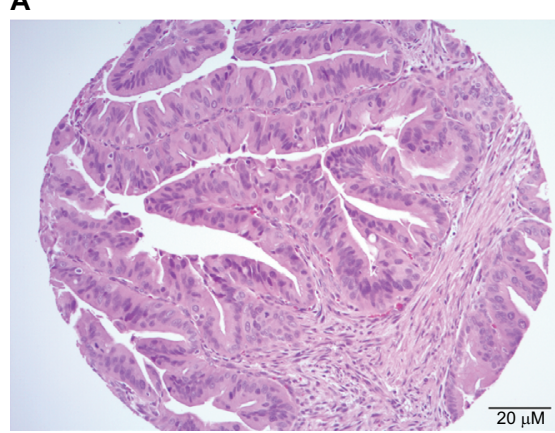

B

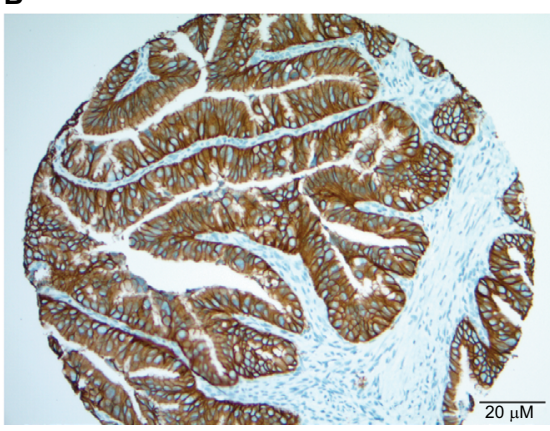

C

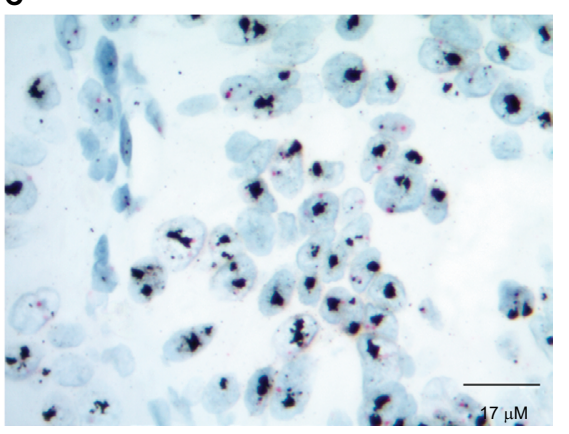

Figure I Extrahepatic Cholangiocarcinoma and Her-2/neu testing.

Notes: (A) A well-differentiated to moderately differentiated adenocarcinoma of the bile duct showing an invasive tumor with papillary morphology and associated desmoplastic stroma. The tumor cells have pink cytoplasm and elongated to polygonal nuclei with anisocytosis and loss of polarity (hematoxylin and eosin, $40 \times$ ). (B) The adenocarcinoma shown in Figure IA is strongly and diffusely positive for Her-2/neu (3+) and exhibits a well-defined membranous pattern of stain (40x). (C) Dual in situ hybridization demonstrating amplification of human epidermal growth factor receptor- 2 in a moderately differentiated adenocarcinoma.

evidence of metastatic disease to the lymph nodes or distant organs $\left(\mathrm{T}_{1} \mathrm{~N}_{0} \mathrm{Mx}\right)$.

The entire TMA was evaluated using DISH as part of this study, regardless of the IHC results. The DISH results demonstrated Her-2/neu amplification (ratio $>2$ ) in 2 cases ( 6 cores). One of these Her-2/neu-positive cases was the one that was found to be positive by IHC (Figure 1C).

\section{Discussion}

In the current study, we examined Her-2/neu protein expression in EHBC and found only 1 out of 43 cases $(2.3 \%)$ to overexpress Her-2/neu. All the NNB samples were Her-2/ neu negative.

Our results are in agreement with a few other reported studies investigating Her-2/neu protein expression in EHBC.

In one of these studies, Shafizadeh et al showed Her-2/neu expression in 2 out of 19 (4\%) EHBC cases. These positive cases had a moderate and diffuse Her-2/neu staining (IHC score 2). The patients with positive Her-2/neu tumors were reported to have tumors of high grade and high stage upon presentation. ${ }^{15}$ This result is in disagreement with our finding where the only Her-2/neu-positive tumor was a moderately differentiated adenocarcinoma stage 1.

Yoshikawa et al reported their analysis of a larger group of EHBC patients where they observed the expression of Her-2/ neu in 11 out of $130(8.5 \%)$ EHBC patients. These authors described the Her-2/neu expression in well-differentiated and moderately differentiated tumors. ${ }^{16}$

The original study by Nakazawa et al compared the Her-2/ neu expression in $\mathrm{EHBC}$ and in gallbladder carcinomas. They found significant expression of Her-2/neu in 14 out of 89 $(15.7 \%)(P<0.05)$ gall bladder carcinomas, compared to only 4 out of 78 (5\%) EHBC. ${ }^{17}$ All (100\%) 3+ Her-2/neu and 67\% of $2+$ Her-2/neu tumors showed Her-2/neu gene amplification as well. These authors speculated that Her-2/neu protein is expressed in early EHBC disease and it is subsequently lost in late advanced EHBC disease. ${ }^{17}$

Other studies have reported higher percentage of Her-2/ neu protein expression in EHBC. For example, Kim et al showed Her-2/neu protein expression in 16 out of 55 cases (29\%) of EHBC with an IHC score of either 2 or $3 .{ }^{18}$ These authors also detected Her-2/neu gene amplification in 10 out of 55 patients (18\%). Although there was no significant correlation between HER-2/neu protein expression and gender, age, location, tumor size, histologic grade, TNM Classification of Malignant Tumors stage, and presence or absence of lymphatic or perineural invasion, HER-2/neu protein overexpression tended to have a higher rate of distant metastasis. ${ }^{18}$

Zheng and Zhu reported an even higher percentage (60 of 75 cases; $80 \%$ ) of EHBC with Her-2/neu overexpression. Her-2/neu expression in EHBC was commonly seen in high histological grade tumors compared to grade I tumors $(P<0.05)$. Perineural invasion and distant metastasis was significantly $(P<0.05)$ related to Her-2/neu-positive tumors. ${ }^{19}$

Expression of Her-2/neu, a tyrosine kinase receptor, in cancer has a great clinical significance due to the fact that this receptor can be targeted pharmaceutically. Numerous trials in breast cancer, ${ }^{20,21}$ stomach cancer, ${ }^{12,13,22}$ and bladder cancer ${ }^{23,24}$ have shown the therapeutic benefit of targeting Her-2/neu with adjuvant therapy, especially in the metastatic setting.

Reports of isolated cases of patients with Her-2/neupositive metastatic gall bladder and pancreatobiliary tumors effectively responding to adjuvant therapy ${ }^{25,26}$ have raised the hope that EHBC could be therapeutically targeted. However, our results did not show a high percentage of Her-2/neupositive EHBC. The discrepancy with earlier reports, showing a higher percentage of Her-2/neu-positive EHBC, may be due to the different type of antibody used (Table 2), or 
Table 2 Her-2/neu antibodies used in the current study compared to others

\begin{tabular}{|c|c|c|}
\hline Author & Method & Antibody source \\
\hline Kim et al $(2007)^{18}$ & Manual & $\begin{array}{l}\text { Zymed lab, South San } \\
\text { Francisco, CA, USA }\end{array}$ \\
\hline $\begin{array}{l}\text { Yoshikawa et al } \\
(2008)^{16}\end{array}$ & $\begin{array}{l}\text { Automated (polymer-based } \\
\text { method, EnVision + Dual } \\
\text { Link System-HRP) }\end{array}$ & $\begin{array}{l}\text { Dako Denmark A/S, } \\
\text { Glostrup, Denmark }\end{array}$ \\
\hline $\begin{array}{l}\text { Zheng and Zhu } \\
(2007)^{19}\end{array}$ & Manual & $\begin{array}{l}\text { Dako Denmark A/S, } \\
\text { Glostrup, Denmark }\end{array}$ \\
\hline $\begin{array}{l}\text { Nakazawa et al } \\
(2005)^{17}\end{array}$ & Manual & Nichirei, Tokyo, Japan \\
\hline $\begin{array}{l}\text { Shamekh et al } \\
\text { (present study) }\end{array}$ & $\begin{array}{l}\text { Automated (Ventana } \\
\text { Medical Systems, using } \\
\text { the Benchmark XT) }\end{array}$ & $\begin{array}{l}\text { Ventana Medical } \\
\text { Systems, Inc. Tucson, } \\
\text { AZ, USA }\end{array}$ \\
\hline
\end{tabular}

Abbreviations: Her-2, human epidermal growth factor receptor-2; HRP, horseradish peroxidase.

to the preanalytical factors such as warm and cold ischemic time, type of fixative, time of fixation, and so on. Some of the previous studies were conducted before the publication of the College of American Pathologists guidelines for Her-2/ neu testing, ${ }^{14}$ and their authors may have used different tissue preparation and IHC scoring criteria.

In conclusion, we found that Her-2/neu expression in EHBC is a rare event. Our finding is in agreement with a portion of the current literature on this topic.

\section{Acknowledgments}

The authors thank the Histology and Immunohistochemical Laboratory of the Anatomic Pathology Department at the Moffitt Cancer Center for performing immunohistostaining and DISH testing.

Kathy Bryant is thanked for her editing and assistance in the submission of the paper.

\section{Disclosure}

The authors report no conflicts of interest in this work.

\section{References}

1. Blechacz B, Komuta M, Roskams T, Gores GJ. Clinical diagnosis and staging of cholangiocarcinoma. Nat Rev Gastroenterol Hepatol. 2011; 8(9):512-522.

2. Everhart JE, Ruhl CE. Burden of digestive diseases in the United States Part III: liver, biliary tract, and pancreas. Gastroenterology. 2009;136(4):1134-1144

3. Shaib Y, El-Serag HB. The epidemiology of cholangiocarcinoma. Semin Liver Dis. 2004;24(2):115-125.

4. Charbel H, Al-Kawas FH. Cholangiocarcinoma: epidemiology, risk factors, pathogenesis, and diagnosis. Curr Gastroenterol Rep. 2011;13(2): $182-187$.

5. Suto T, Habano W, Sugai T, et al. Aberrations of the K-ras, p53, and APC genes in extrahepatic bile duct cancer. J Surg Oncol. 2000;73(3): $158-163$.
6. Yang JL, Klinkebiel D, Boland MJ, Tang L, Christman JK. [Promoter methylation and mRNA expression of MCF10 model cell lines of breast cancer]. Zhonghua Bing Li Xue Za Zhi. 2005;34(3):177-178.

7. Moasser MM. The oncogene HER2: its signaling and transforming functions and its role in human cancer pathogenesis. Oncogene. 2007;26(45):6469-6487.

8. Slamon DJ, Godolphin W, Jones LA, et al. Studies of the HER-2/neu proto-oncogene in human breast and ovarian cancer. Science. 1989; 244(4905):707-712.

9. Yokota J, Yamamoto T, Toyoshima K, Terada M, Sugimura T, Battifora $\mathrm{H}$, Cline MJ. Amplification of c-erbB-2 oncogene in human adenocarcinomas in vivo. Lancet. 1986;1(8484):765-767.

10. Almhanna K, Rosa M, Henderson-Jackson E, et al. Her-2 expression in gastroesophageal intestinal metaplasia, dysplasia, and adenocarcinoma. Appl Immunohistochem Mol Morphol. Epub 2015 Jul 16.

11. Russo G, Zegar C, Giordano A. Advantages and limitations of microarray technology in human cancer. Oncogene. 2003;22(42):6497-6507.

12. Hofmann M, Stoss O, Shi D, et al. Assessment of a HER2 scoring system for gastric cancer: results from a validation study. Histopathology. 2008;52(7):797-805.

13. Bang YJ, Van Cutsem E, Feyereislova A, et al. Trastuzumab in combination with chemotherapy versus chemotherapy alone for treatment of HER2-positive advanced gastric or gastro-oesophageal junction cancer (ToGA): a phase 3, open-label, randomised controlled trial. Lancet. 2010;376(9742):687-697.

14. Ruschoff J, Hanna W, Bilous M, Hofmann M, et al. HER2 testing in gastric cancer: a practical approach. Mod Pathol. 2012;25(5):637-650.

15. Shafizadeh N, Grenert JP, Sahai V, Kakar S. Epidermal growth factor receptor and HER-2/neu status by immunohistochemistry and fluorescence in situ hybridization in adenocarcinomas of the biliary tree and gallbladder. Hum Pathol. 2010;41(4):485-492.

16. Yoshikawa D, Ojima H, Iwasaki M, et al. Clinicopathological and prognostic significance of EGFR, VEGF, and HER2 expression in cholangiocarcinoma. Br J Cancer. 2008;98(2):418-425.

17. Nakazawa K, Dobashi Y, Suzuki S, Fujii H, Takeda Y, Ooi A. Amplification and overexpression of c-erbB-2, epidermal growth factor receptor, and c-met in biliary tract cancers. J Pathol. 2005;206(3): 356-365.

18. Kim HJ, Yoo TW, Park DI, et al. Gene amplification and protein overexpression of HER-2/neu in human extrahepatic cholangiocarcinoma as detected by chromogenic in situ hybridization and immunohistochemistry: its prognostic implication in node-positive patients. Ann Oncol. 2007;18(5):892-897.

19. Zheng J, Zhu YM. Expression of c-erbB-2 proto-oncogene in extrahepatic cholangiocarcinoma and its clinical significance. Hepatobiliary Pancreat Dis Int. 2007;6(4):412-415.

20. Hudis CA. Trastuzumab--mechanism of action and use in clinical practice. $N$ Engl J Med. 2007;357(1):39-51.

21. Milani A, Montemurro F, Gioeni L, Aglietta M, Valabrega G. Role of trastuzumab in the management of HER2-positive metastatic breast cancer. Breast Cancer (Dove Med Press). 2010;2:93-109.

22. Croxtall JD, McKeage K. Trastuzumab: in HER2-positive metastatic gastric cancer. Drugs. 2010;70(17):2259-2267.

23. Peyromaure M, Scotte F, Amsellem-Ouazana D, Vieillefond A, Oudard $\mathrm{S}$, Beuzeboc P. Trastuzumab (Herceptin) in metastatic transitional cell carcinoma of the urinary tract: report on six patients. Eur Urol. 2005;48(5):771-775; discussion 775-778.

24. Salzberg M, Borner M, Bauer JA, Morant R, Rauch D, Rochlitz C. Trastuzumab (Herceptin) in patients with HER-2-overexpressing metastatic or locally advanced transitional cell carcinoma of the bladder: report on 7 patients. Eur J Cancer. 2006;42(15):2660-2661.

25. Law LY. Dramatic response to trastuzumab and paclitaxel in a patient with human epidermal growth factor receptor 2-positive metastatic cholangiocarcinoma. J Clin Oncol. 2012;30(27):e271-e273.

26. Sorscher $\mathrm{S}$. Marked radiographic response of a HER-2-overexpressing biliary cancer to trastuzumab. Cancer Manag Res. 2013;9:1-3. 
Pathology and Laboratory Medicine International

Publish your work in this journal

Pathology and Laboratory Medicine International is a peer-reviewed, open access journal focusing on innovative basic research and translational research related to pathology or human disease. The journal includes original research, updates, case reports, reviews and commentaries on current controversies. The manuscript management system is completely
Dovepress

online and includes a very quick and fair peer-review system. Visit http://www.dovepress.com/testimonials.php to read real quotes from published authors.

Submit your manuscript here: https://www.dovepress.com/pathology-and-laboratory-medicine-international-journal 